\title{
Schwann Cells Stimulated to Proliferate in the Absence of Neurons Retain Full Functional Capability
}

\author{
Seth Porter, M. Blair Clark, ${ }^{\star} \dagger$ Luis Glaser, and Richard P. Bunge* \\ Department of Biological Chemistry, *Anatomy and Neurobiology, and †The McDonnell Center for Studies of Higher \\ Brain Function, Washington University School of Medicine, St. Louis, Missouri 63110
}

Schwann cells from neonatal rat sciatic nerve can be maintained and grown in culture in the absence of neurons. We are interested in substantially expanding such cultures for use in the study of Schwann cells, their growth responses, and their interactions with neurons. However, it was important to determine if expanded cell populations retained their distinguishing biological properties and their ability to differentiate when recombined with neurons. 'Therefore, we have compared the functional properties of extensively expanded populations of sciatic nerve Schwann cells to those of embryonic dorsal root ganglion (DRG) Schwann cells that had been briefly expanded in vitro in the continuous presence of ganglion neurons. Sciatic nerve Schwann cells were cultured and purified according to the methods of Brockes et al. (1979). A combination of crude glial growth factor and forskolin was found to act synergistically in providing maximal stimulation of Schwann cell proliferation. Sciatic nerve Schwann cells that were continuously expanded for at least 2 months were compared to Schwann cells derived from fetal dorsal root ganglia. The results indicate that (1) the complement of secreted proteins from both cell populations, either in isolation or recombined with neurons, was essentially identical; (2) both cell populations expressed the cell-surface antigens laminin and Ran 1 (217C antibody); (3) after seeding onto DRG neurons, both cell populations associated with neuronal processes with the same time course; and (4) under identical nutrient conditions, both cell populations were observed to exhibit a comparable capacity for myelination of DRG axons in vitro. Thus, methods used to establish primary cultures of rat sciatic nerve Schwann cells and to expand secondary cultures in vitro in the absence of neurons preserve basic Schwann cell functions.

The establishment of neuron-Schwann cell cocultures from dorsal root ganglia (DRG) of embryonic rats has provided a convenient system for the study of the interactions of 2 distinct cell types (Wood, 1976). Schwann cells in these cultures closely associate with neuronal processes and, under a wide variety of culture conditions, will proliferate in response to a neuronalsurface mitogen (Salzer and Bunge, 1980; Salzer et al., 1980a, b; Wood, 1976). A component of this axonal mitogen is now known to be a heparan sulfate proteoglycan (Ratner et al. 1985). The neuron-associated Schwann cells can also differentiate in vitro by assembling a basal lamina (M. B. Bunge et al., 1980, 1982), ensheathing smaller axons, and providing a myclin shcath

Received Mar. 11, 1986; revised Apr. 30, 1986; accepted May 5, 1986.

The authors would like to thank Dr. M. Schachner for providing antibodies against N-CAM, L1, L2, and J1. This work was supported by NIH Grants NS19923 and NS0992.3. Fellowship support to $S$. Porter was from the American Cancer Society (PF-2488) and the National Institutes of Health (NS07551).

Correspondence should be addressed to Dr. Seth Porter, Department of Biological Chemistry, Washington University School of Medicine, $660 \mathrm{~S}$. Euclid Ave. St. Louis, MO 63110.

Copyright (C) 1986 Society for Neuroscience $0270-6474 / 86 / 103070-09 \$ 02.00 / 0$ for axons of $1 \mu \mathrm{m}$ or more in diameter (Wood, 1976). Thus it is possible to demonstrate functional interactions between neurons and Schwann cells at several levels, and to recreate in vitro many of the events known to occur in vivo during development of the peripheral nervous system.

It is difficult, however, to generate from the cocultures the numbers of Schwann cells needed to characterize at a molecular level the nature and mechanism of the functional association of these 2 cell types. It would therefore be beneficial to have a source of large numbers of Schwann cells that, when combined with neurons, would exhibit the same interactive potential as the cells from primary cultures of embryonic DRG. Brockes and associates have described methods for isolating Schwann cells from the sciatic nerve of perinatal rats and effectively removing the contaminating fibroblasts (Brockes et al., 1979). These Schwann cells proliferate very slowly in the absence of neurons (Brockes et al., 1979), but can be stimulated to proliferate in response to crude or purified preparations of glial growth factor (GGF) derived from bovine pituitaries (Brockes et al., 1979; Kreider et al., 1982; Lemke and Brockes, 1984; Raff et al., $1978 \mathrm{a}, \mathrm{b})$, as well as to cholera toxin, an activator of adenylate cyclase. It has been suggested that GGF and cholera toxin induce proliferation through different mechanisms and thus can work together to yield additive results (Raff et al., 1978a). Others have used modifications of the Brockes technique for Schwann cell isolation, choosing to use less severe methods for removal of non-Schwann cells (Kalderon, 1984; Kreider et al., 1981) for fear of possible deleterious effects of antimitotic agents. Positively charged substrates have also been found to be beneficial for maintenance of sciatic nerve Schwann cells (Kreider et al., 1981).

The present studies were initiated with the intent of developing methods for generating large numbers of Schwann cells that retain normal growth properties. While cholera toxin is an effective agent for expanding Schwann cell cultures, we were concerned about the slow reversibility of its effect. Cholera toxin induces a covalent ADP-ribosylation of the regulatory subunit of adenylate cyclase, thereby irreversibly activating the enzyme and generating high levels of intracellular cAMP (Cassel and Pfeuffer, 1978; Gill and Meren, 1978). The mechanism whereby cAMP promotes Schwann cell proliferation is as yet unknown. Because the toxin-induced modification is covalent, mere removal from the culture medium would not cause immediate reversal of its effects. Raff et al. (1978b) reported that a $3 \mathrm{~d}$ exposure of cells to cholera toxin was sufficient to maintain proliferation for more than 2 weeks. Only gradual turnover of the adenylate cyclase protein could lead to an eventual decline in toxin effects. We have chosen instead to use forskolin, a diterpene drug which activates adenylate cyclase by noncovalent association with the enzyme (Seamon and Daly, 1981b). Because it is bound noncovalently, its effects are more readily reversible. By combining low concentrations of forskolin with 
a partially purified extract of bovine pituitaries, we can achieve a high level of proliferation in sciatic nerve-derived Schwann cells. Furthermore, if the cells are maintained on a poly-L-lysine (PLL) substratum, confluent monolayers of the cells can be attained that, over a period of at least 2 months, retain normal growth characteristics after removal of the mitogenic mixture.

We were concerned that the manipulations required for extensive expansion of sciatic nerve Schwann cells might yield cells that were functionally different from DRG Schwann cells that had maintained their association with neurons and were capable of functional interactions with these neurons. We have therefore compared the biological activities expressed by the 2 Schwann cell populations and report here that they are essentially identical.

\section{Materials and Methods}

\section{Materials}

One to 3-d-old Sprague-Dawley-derived rats were obtained from Chappel Breeders (St. Louis, MO) and frozen bovine pituitaries were purchased from Pel-Freez Biologicals (Rogers, AZ). Tissue-culture plastic was purchased from Falcon (Oxnard, $\mathrm{CA}$ ) and multi-well tissue-culture slides came from Miles (Elkhart, IN). Fetal bovine serum was obtained from K.C. Biologicals (Kansas City, MO) and Gibco (Grand Island, NY); tissue-culture media were acquired from the Media Center at Washington University Medical School. Radionuclides came from New England Nuclear (Boston, MA). Collagenase (Type I) and TPCK-trypsin were from Cooper Biomedical (Malvern, PA), forskolin from Calbiochem (La Jolla, C.A), and poly-t.-lysine from Sigma (St. Louis, MO).

\section{Sciatic nerve Schwann cell culture}

Sciatic nerve Schwann cells were prepared and purified according to the methods of Brockes et al. (1979). Briefly, sciatic nerves were dissected from neonatal rats, dissociated with $0.1 \%$ collagenase and $0.25 \%$ trypsin in L-15 medium, and plated on tissue-culture plastic in Dulbecco's Modified Eagle's Medium (DMEM) plus $10 \%$ fetal calf serum (FCS). After 18-24 hr, the medium was changed to one containing $10^{-5} \mathrm{M}$ cytosine arabinoside. Three days later, the cells were suspended with $0.05 \%$ trypsin, $0.02 \%$ EDTA in calcium- and magnesium-free Hanks' balanced salts, and treated for 30 min each with anti-Thyl.1 and rabbit complement. Typically, the anti-Thy 1.1 and complement treatment was repeated 2-3 d later, prior to plating cells in DMEM plus $10 \%$ FCS. For long-term culture, cells were plated onto $100 \mathrm{~mm}$ poly-L-lysine- (PLL) coated tissue-culture dishes at a density of $3 \times 10^{6} / \mathrm{dish}$. After $24 \mathrm{hr}$ medium containing $2 \mu \mathrm{M}$ forskolin and $10 \mu \mathrm{g} / \mathrm{ml} \mathrm{GGF}$ was added and not replenished. Seven to $10 \mathrm{~d}$ later, cells were trypsinized, treated with anti-Thy 1.1 and complement, replated, and mitogen-stimulated as before.

\section{$D R G$ neuron and Schwann cell culture}

Mcdia formulations used for thesc preparations have been described previously (M. B. Bunge et al., 1980; Carey and Bunge, 1981; Moya et al., 1980; Wood, 1976). C-10 is Earle's Minimal Essential Medium (EMEM; Gibco) plus 10\% human placental serum (HPS), $50 \mathrm{ng} / \mathrm{ml}$ NGF, $17.5 \mathrm{~mm}$ glucose, and $2 \mathrm{~mm}$ glutamine. $\mathrm{CF}$ is $\mathrm{C}-10$ plus $2 \times 10^{-5}$ $\mathrm{M}$ fluorodeoxyuridine (FUdR) and uridine. E-15 is the same as C-10, only containing $15 \% \mathrm{HPS}, 50 \mathrm{ng} / \mathrm{ml} \mathrm{NGF}$, and $50 \mu \mathrm{g} / \mathrm{ml}$ ascorbate (Eldridge et al., 1985). N2 is the medium defined by Bottenstein and Sato (1979), supplemented with $100 \mathrm{ng} / \mathrm{ml} \mathrm{NGF}$.

Primary cultures of DRG neurons were prepared as described by Wood (1976), except that trypsin-dissociated cell cultures were used instead of ganglia. Cells were plated at a density equivalent to 40 ganglia/ $35 \mathrm{~mm}$ collagen-coated dish; in some cases, 3 drops of dissociated cells, containing the equivalent of 2 ganglia/drop, were spaced equidistantly onto a $35 \mathrm{~mm}$ collagen-coated dish. After a 2 week treatment with FUdR (Wood, 1976), the pure neuron cultures were seeded with purified Schwann cells obtained from intact primary DRG cultures (Wood, 1976) or from sciatic nerve, at $2.5 \times 10^{4}$ cells $/ 35 \mathrm{~mm}$ culture dish in $\mathrm{C}-10$ Two different cultures of sciatic nerve Schwann cells that had been expanded and passaged as described were used in these experiments. One was tested 2 months ( 6 passages) and 8 months ( 24 passages) after dissection and the other 1 month after dissection. After $1 \mathrm{~d}$, seeded cultures were switched to and maintained in N2-defined medium. Three weeks later, some cultures were switched to E-15, which promotes myelination. Other cultures were maintained in $\mathrm{N} 2$ to prevent myelination from occurring.

\section{Metabolic labeling and SDS gel electrophoresis}

After 3 weeks in E-15, when cultures were heavily myelinated, 2 myelinated cultures from each group (sciatic nerve or DRG Schwann cells), 1 nonmyelinated culture (maintained in N2 medium) from each group, and pure Schwann cell cultures were metabolically labeled with ${ }^{3} \mathrm{H}$ leucine. Labeling medium was leucine-free EMEM with $100 \mathrm{ng} / \mathrm{ml} \mathrm{NGF}$, $50 \mu \mathrm{g} / \mathrm{ml}$ ascorbate, $2 \mathrm{mM}$ glutamine, and $200 \mu \mathrm{Ci} / \mathrm{ml}{ }^{3} \mathrm{H}$-leucine. After a $24 \mathrm{hr}$ pulse, medium was collected on ice, and EDTA (10 mM), $N$-ethylmaleimide $(0.1 \mathrm{mg} / \mathrm{ml})$, and phenylmethylsulfonylfuoride $(0.1 \mathrm{ng} / \mathrm{ml})$ were added to each. Equal volumes of conditioned media were separated on a $10 \%$ SDS polyacrylamide gel, as described by Laemmli (1970). Gels were fixed overnight in 10\% trichloroacetic acid, 10\% acetic acid, $30 \%$ methanol, prepared for fluorography with ENHANCE (NEN, Boston), and exposed for 2 weeks to preflashed Kodak XR film at $-70^{\circ} \mathrm{C}$.

\section{Preparation of glial growth factor}

A partially purified preparation of GGF from frozen bovine pituitaries was made per Brockes et al. (1980). The activity eluted from CMSephadex with $0.2 \mathrm{M} \mathrm{NaCl}$ was dialyzed against water, lyophilized, and the dry powder stored at $-20^{\circ} \mathrm{C}$.

\section{Assay of Schwann cell proliferation}

${ }^{3} \mathrm{H}$-thymidine uptake was assayed by autoradiography. Schwann cells were plated on PLL-coated 8-well culture slides, $15 \times 10^{3} /$ well. After $24 \mathrm{hr}$, mitogen was added for varying periods of time, although the medium was always changed every 2 days. ${ }^{3} \mathrm{H}$-thymidine was added for the last $24 \mathrm{hr}$ at $3 \mu \mathrm{Ci} / \mathrm{ml}$. Cells were fixed with $4 \%$ glutaraldehyde in $10 \mathrm{~mm}$ Tris, $\mathrm{pH} 7.4,150 \mathrm{~mm} \mathrm{NaCl}$, washed in $\mathrm{H}_{2} \mathrm{O}$ and coated with emulsion (NTB-2; Kodak). Slides were exposed for $3 \mathrm{~d}$ at $4^{\circ} \mathrm{C}$, developed and stained with toluidine blue. Five hundred to 1000 cells were counted for each determination. For cell-number determinations, $2 \times 10^{5}$ cells were plated in duplicate $35 \mathrm{~mm}$ PLL-coated dishes. After $24 \mathrm{hr}$, mitogen was added and replenished every $48 \mathrm{hr}$. At the indicated times, cells were suspended with trypsin and counted with a hemacytometer.

\section{Immunocytochemistry}

Cells plated on PLL-coated glass coverslips were washed once with L-15 medium plus $10 \%$ horse serum, incubated for $45 \mathrm{~min}$ with antibody diluted in L-15 plus serum, washed 4 times, incubated with goat antimouse or goat anti-rabbit Ig serum conjugated to either a rhodamine or fluorescein chromophore, and washed again. The cells were then fixed with acid-alcohol, the coverslips mounted on slides and visualized on a Zeiss microscope equipped for epifluorescence.

\section{Results}

\section{Mitogens}

For purposes of expanding Schwann cell cultures, we chose to use the partially purified, CM-Sephadex fraction of GGF activity. This preparation gave a dose-dependent stimulation of primary Schwann cells with half-maximal effect at $15 \mu \mathrm{g} / \mathrm{ml}$. Hoping to maximally stimulate proliferation and generate large numbers of Schwann cells, we sought an activator of adenylate cyclase that, like cholera toxin, would yield a large proliferative response but, unlike the toxin, would be readily reversible. Forskolin has been shown to be a potent activator of the cyclase (Seamon and Daly, 1981b), although the mechanism of action is not well defined. While at first thought to bind directly to the catalytic subunit (Seamon and Daly, 1981a), recent evidence suggests that its site of action is the regulatory $\mathrm{N}_{\mathrm{s}}$ subunit (Darfler et al., 1982; Stengel et al., 1982). Most important, forskolin effects have been reported to be readily reversible (Seamon and Daly, 1981b). We tested the effects of forskolin on Schwann cells and found that, like cholera toxin, it is mitogenic for the cells, although little effect on tritiated thymidine uptake was detected at concentrations below $10 \mu \mathrm{M}$. Prolonged exposure to 
$10 \mu \mathrm{M}$ forskolin was toxic. A mixture of $10-20 \mu \mathrm{g} / \mathrm{ml}$ of pituitary extract and a nonmitogenic concentration of forskolin $(2 \mu \mathrm{M})$ had a synergistic effect on thymidine uptake into nuclei after 3 d. While GGF alone induced a $12-15$-fold stimulation of ${ }^{3} \mathrm{H}-$ thymidine, and forskolin provided a $0-3$-fold stimulation, the combination caused a 60 -fold enhancement of nucleotide uptake (Fig. 1). As demonstrated in Figure 1, the cells continued to increase their incorporation of thymidine into nuclei over a period of $5 \mathrm{~d}$, by which time they were reaching confluency. When the mitogenic mixture was removed after $3 \mathrm{~d}$, thymidine uptake declined rapidly, so that by the fourth $d$ after mitogen removal, the cells displayed nucleotide uptake comparable to unstimulated control cells (Fig. 1). Cells that had been treated with mitogen for $3 \mathrm{~d}$, followed by mitogen withdrawal for $4 \mathrm{~d}$, could be restimulated by the mitogenic mixture with apparently the same kinetics as in the initial response. The combination of pituitary extract plus forskolin thus appeared to be an excellent means of generating large numbers of cells that retained a characteristic pattern of response to mitogens, even after being maintained and expanded in culture. It is not clear why the response to mitogens declines after prolonged, continuous exposure. In cultures containing both GGF and forskolin, sufficient cell density may have been attained to incur contact inhibition. However, cells treated with GGF alone do not appear to reach high density, which suggests that down-regulation of GGF receptors may occur.

\section{Substratum}

Initial experiments with pituitary extract and forskolin yielded enigmatic results. When plated directly onto glass or plastic, high labeling indices could bc induced in Schwann cell populations. However, we could not achieve the expansion of cultures that such indices would suggest as possible. While detachment of cells from the substratum during mitosis seemed to be the most reasonable explanation, we never observed the number of free-floating cells one would expect under such circumstances. Nonetheless, different substrata were investigated. While ammoniated Type I collagen caused the cells to round up and detach upon mitogen stimulation, PLL yielded much more favorable results. Within $2 \mathrm{~d}$ on PLL in the presence of pituitary extract plus forskolin, Schwann cells began to form a continuous monolayer (Fig. 2). Quantitation of cell number indicated that, on PLL, the cells had a doubling time of $2 \mathrm{~d}$ (Fig. 1). In comparing these results to those obtained on untreated tissue-culture plastic, we concluded that one-half of the mitogen-stimulated cells on plastic alone tended to detach from the substratum during mitosis and that these cells must have lysed or been phagocytosed by the remaining cells. The PLL provides a substratum to which the cells adhere much more avidly and thus remain attached even during mitosis.

\section{Morphology}

Like cholera toxin (Brockes and Raff, 1979), forskolin caused Schwann cells to lose their characteristic spindle shape and to attain a more fibroblast-like broad and extended appearance. These same cells could be trypsinized and replated in the absence of forskolin, whereupon they would return to the more typical Schwann cell morphology, again indicating the reversibility of forskolin effects. Cultures of Schwann cells treated with GGF plus forskolin would eventually form whirling confluent monolayers (Fig. 2). Although the growth rate of cells in confluent cultures decreased (Fig. 1), proliferation in the presence of mitogens continued, with the cells wedging themselves into more compact parallel alignment.

\section{Comparative properties of cultured cells}

Because the physiological role for GGF remains undefined, it is not known whether Schwann cells in vivo are ever exposed
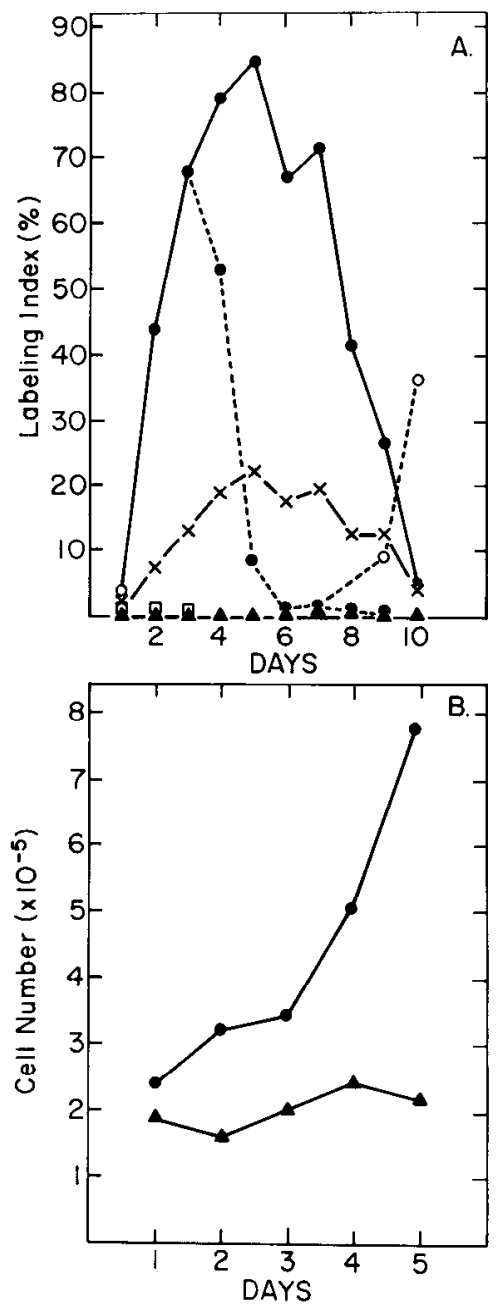

Figure 1. Growth response to glial growth factor and forskolin. A, Primary sciatic nerve Schwann cells were plated onto PLL-coated multiwell glass slides. After $24 \mathrm{hr}$, cells were treated for the indicated times with mitogen. Fresh medium was provided every $48 \mathrm{hr}$. Cells were pulsed with $3 \mu \mathrm{Ci} / \mathrm{ml}{ }^{3} \mathrm{H}$-thymidine for the last $24 \mathrm{hr}$ prior to fixation and processing for autoradiography. ( $\Delta)$, Control, no mitogen added; (口), $2 \mu \mathrm{M}$ forskolin; $(\times), 20 \mu \mathrm{g} / \mathrm{ml} \mathrm{GGF}$; $(-), 20 \mu \mathrm{g} / \mathrm{ml} \mathrm{GGF}, 2 \mu \mathrm{M}$ forskolin; (-- $(-), 20 \mu \mathrm{g} / \mathrm{ml} \mathrm{GGF,} 2 \mu \mathrm{M}$ forskolin for $3 \mathrm{~d}$, followed by medium alone; $(\mathrm{O}---\mathrm{O}), 20 \mu \mathrm{g} / \mathrm{ml}$ GGF, $2 \mu \mathrm{M}$ forskolin removed on day 3 and then re-added on day 7. B, Primary sciatic nerve Schwann cells were plated in PLL-coated $35 \mathrm{~mm}$ tissue-culture dishes. After 48 $\mathrm{hr}$, cells were treated with (•) or without $(\Delta) 20 \mu \mathrm{g} / \mathrm{ml} \mathrm{GGF}$ plus $2 \mu \mathrm{M}$ forskolin. Medium was replenished every $48 \mathrm{hr}$. At the indicated time after mitogen addition, cells in duplicate dishes were suspended with trypsin and counted in a hemacytometer.

to its effects. Presumably, Schwann cells proliferate during development in response to the neuronal cell-surface mitogen (Aguayo et al., 1976; Asbury, 1967; Salzer et al., 1980a). Certainly, Schwann cells do not normally come in contact with forskolin. Therefore, the possibility that the combination of these agents might alter the ability of these cells to differentiate cannot be discounted. Moreover, it is possible that the mitogenic mixture and culture conditions actually selected for a nonSchwann cell contaminant that preferentially responded to the mitogens and eventually dominated the cultures. For these reasons, it was necessary to determine if the Schwann cells that were maintained and expanded in vitro, as described above, would still elicit properties characteristic of normal Schwann cells. The properties that we chose to investigate were (1) cell- 


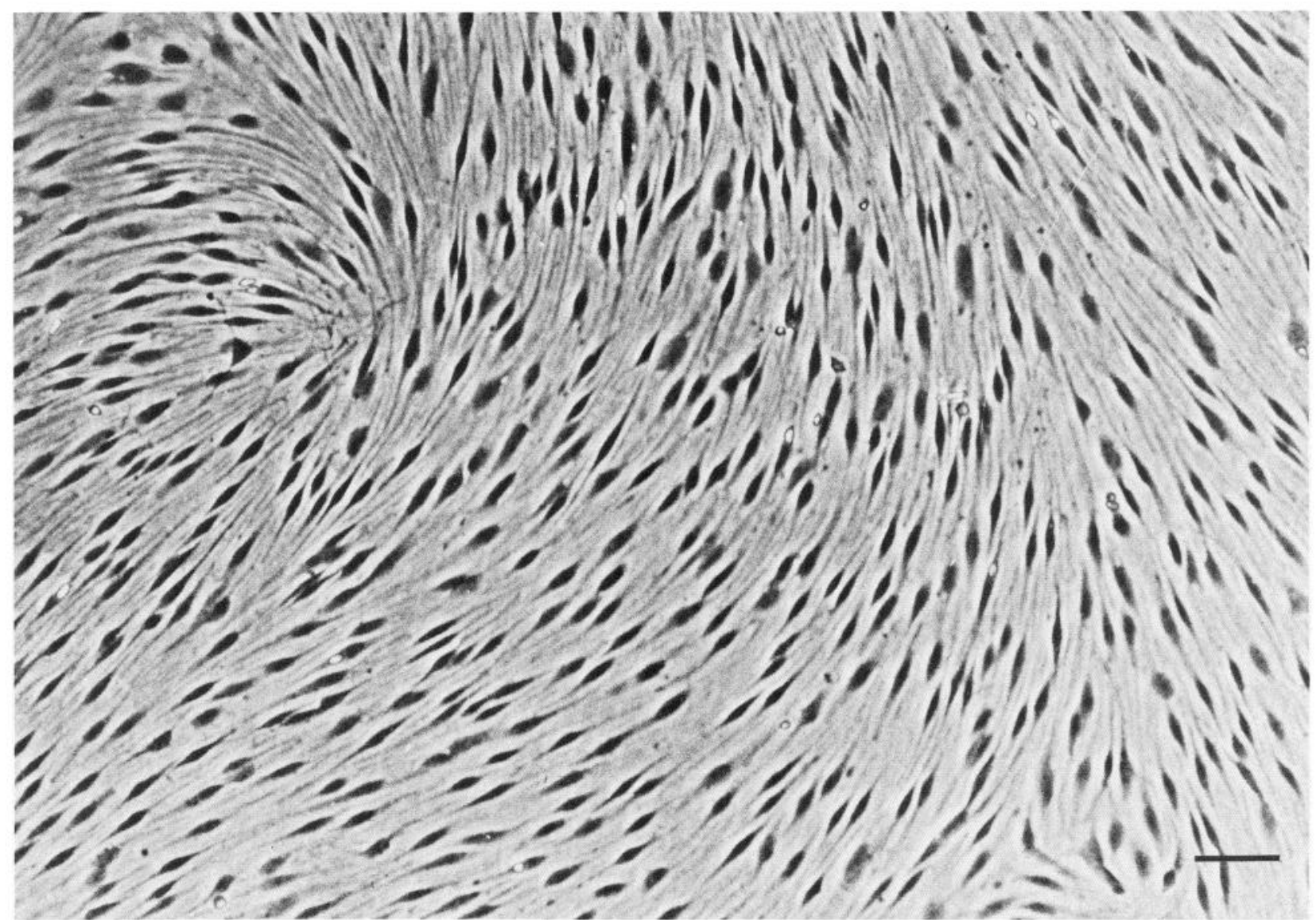

Figure 2. Morphology of mitogen-stimulated Schwann cells. Primary sciatic nerve Schwann cells were plated on a PLL-treated tissue-culture dish and treated for $8 \mathrm{~d}$ with $20 \mu \mathrm{g} / \mathrm{ml} \mathrm{GGF}, 2 \mu \mathrm{M}$ forskolin. Phase micrograph of a living culture. Bar, $20 \mu \mathrm{m}$.

surface antigenic markers, (2) secretory proteins, (3) the ability to recognize and associate with neurons in culture, and (4) the ability to form myelin.

\section{Cell-surface antigens}

The Ran 1 antigen described by Fields et al. (1975) remains one of the few unique surface markers of Schwann cells. When a monoclonal antibody developed by de Vellis against an antigen similar to Ran 1 was used (Fields and Dammerman, 1985; Peng et al., 1982), the cultured cells stained very intensely. The cells also stained in a pattern very similar to that of primary DRG Schwann cells with antibodies to laminin, a major secretory product of the Schwann cell (Cornbrooks et al., 1983) (Fig. 3). Primary and secondary expanded Schwann cell populations stained equally well with antibodies specific to N-CAM and the $\mathrm{L} 1, \mathrm{~L} 2$, and $\mathrm{J} 1$ antigens described by Schachner and her colleagues (Kruse et al., 1984, 1985; Rathjen and Schachner, 1984) (data not shown). Staining with the anti-Thy1.1 monoclonal antibody allowed for assessment of fibroblast contamination in these cultures. The staining pattern was very sparse and indicated a degree of fibroblast contamination well below $1 \%$.

\section{Secretory proteins}

In order to compare mitogen-treated Schwann cells (2 months) to cells grown in the presence of neurons, the proteins of the 2 populations of cells were metabolically labeled in culture with ${ }^{3} \mathrm{H}$-leucine. It had previously been shown that essentially all proteins secreted into the culture medium were of Schwann cell rather than neuronal origin (Carey and Bunge, 1981). Culture media from these cells were collected and the secretory products analyzed by SDS-PAGE followed by autoradiography. The results of this experiment are shown in Figure 4, where the secretory products of the 2 cell populations can be analyzed in parallel. Secretory products elicited under 3 different culture conditions are displayed: Schwann cells and neurons under conditions that promote myelination (Fig. 4, lanes A and B), Schwann cells and neurons in N2-defined medium (Fig. 4, lanes $\mathrm{C}$ and D), and Schwann cells alone (Fig. 4, lanes E and F). While it is apparent that the pattern of secreted components differs somewhat under the 3 different conditions, comparison of the 2 cell populations under each condition reveals nearly indistinguishable patterns. Small quantitative differences can be seen in the proteins secreted by DRG and sciatic nerve cells in the presence of neurons in N2 medium. Within the range of 20,000-40,000 $\mathrm{Da}, \mathrm{DRG}$-derived cells secrete more of a $40 \mathrm{kDa}$ protein and less of 3 other proteins of approximately 35,25 , and $20 \mathrm{kDa}$. In the absence of neurons, the sciatic nerve Schwann cells appear to secrete less of a $100 \mathrm{kDa}$ protein than do DRG cells. The distortion in the gel patterns of lanes A and B (Fig. 4) is caused by serum albumin. The bands corresponding to major secretory products of Schwann cells appear to be of equal intensity.

\section{Association with neurons and myelination}

One of the primary functions of Schwann cells under normal conditions is to isolate axons, either individually or in bundles, and to subsequently ensheathe or myelinate them, depending on axon diameter (Webster and Favilla, 1984). Myelination entails an activity of the Schwann cell that has not yet been 

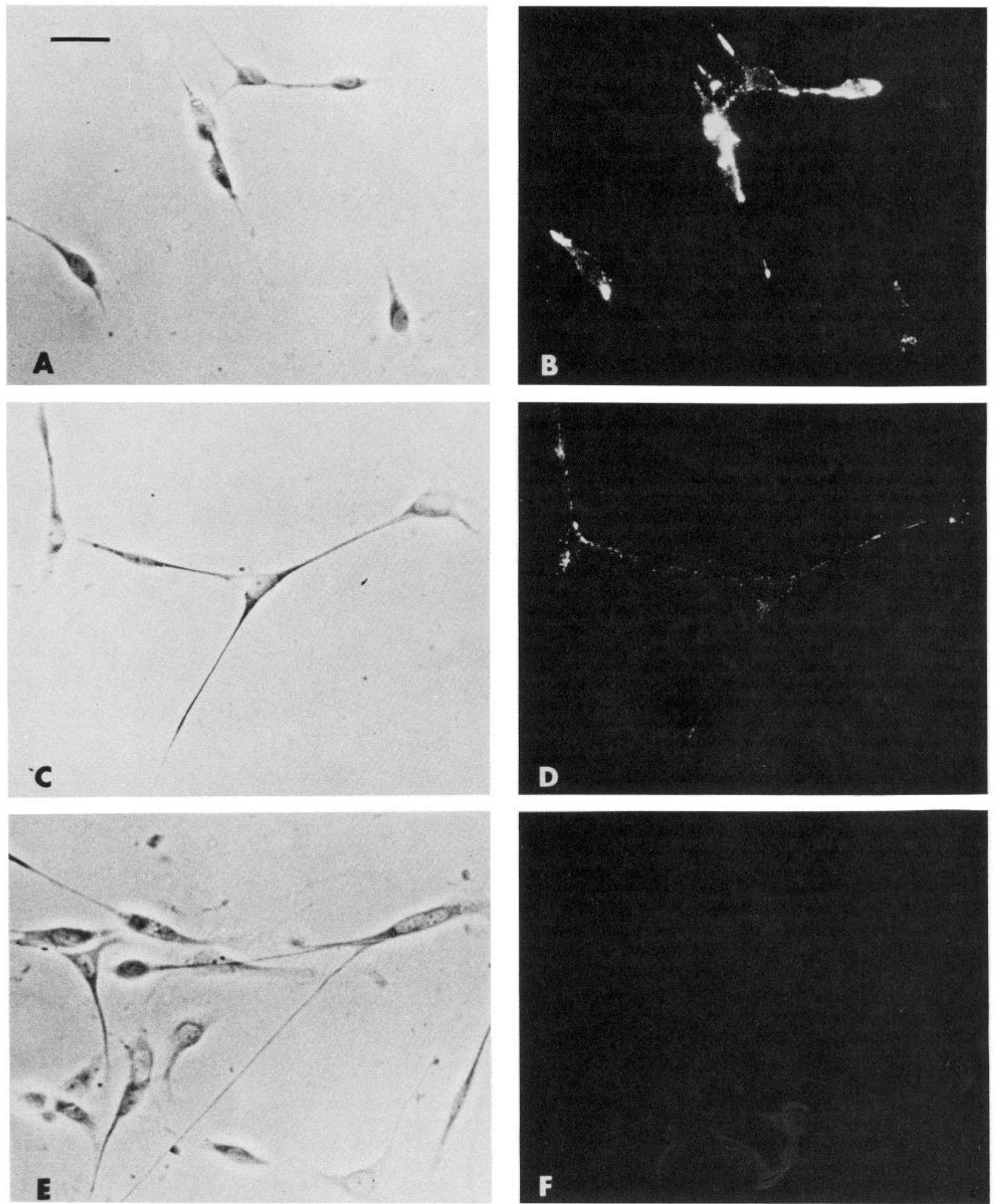

Figure 3. Immunocytochemical detection of Schwann cell surface antigens. Sciatic nerve Schwann cells prepared and expanded in culture, as described in Materials and Methods, for 9 months were plated on PLL-coated glass coverslips. After $48 \mathrm{hr}$, cells were treated with the indicated antibodies (see Materials and Methods) and visualized under phase $(A, C, E)$ and epifluorescence $(B, D, F)$. $A, B$, Mouse monoclonal antibody $217 \mathrm{C}$, considered to recognize the Ran 1 antigen (see text). $C, D$, Rabbit anti-laminin antiserum. $E, F$, Mouse anti-Thy 1.1 monoclonal antibody. Bar in $A, 20 \mu \mathrm{m}$.

completely described in mechanistic terms. During myelination the axon is surrounded with compacted lamellae of Schwann cell plasma membrane. Except for the oligodendrocyte of the CNS, no other cell is known to exhibit such behavior and pro- duce such a distinctive structural entity. The ability to myelinate, therefore, is a definitive measure of Schwann cell character and function.

Expanded populations of sciatic nerve Schwann cells were 

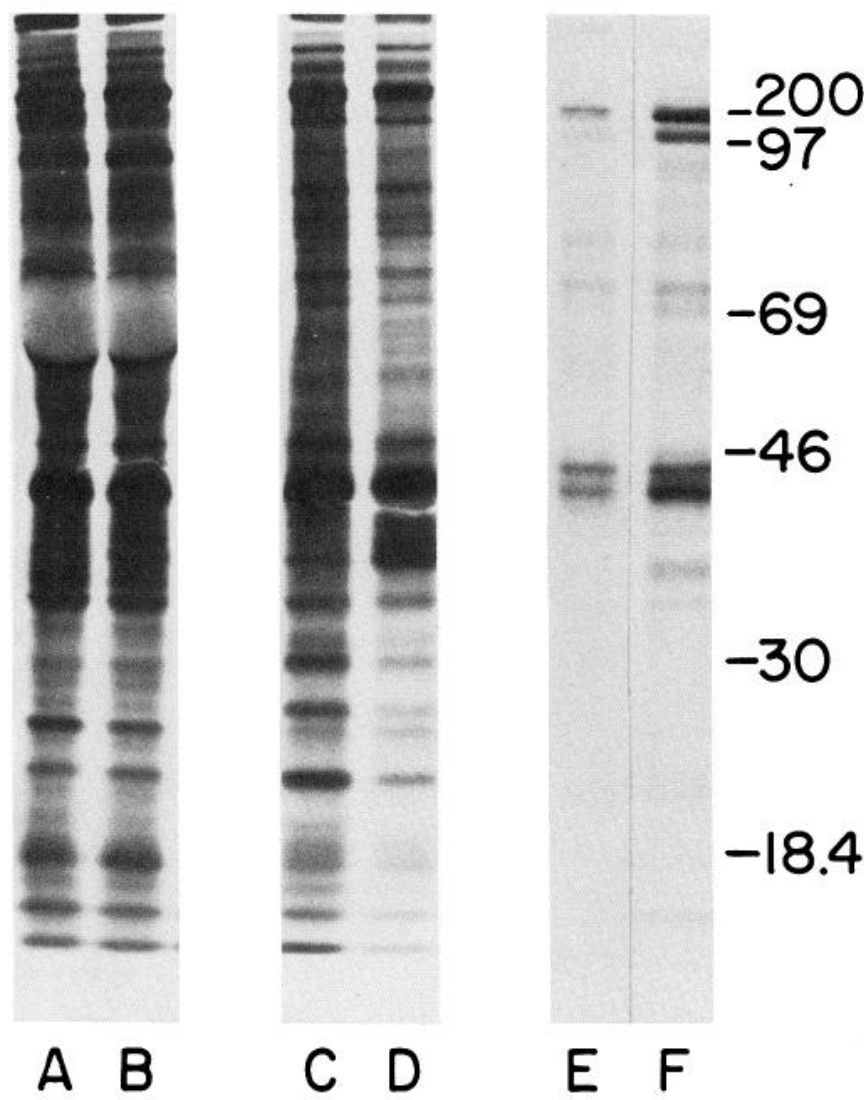

Figure 4. Secretory products of Schwann cells derived from either sciatic nerve or DRG. Pure Schwann cells were isolated from sciatic nerve or DRG and subsequently seeded onto pure neuronal cultures. Secretory products from cultures metabolically labeled with ${ }^{3} \mathrm{H}$-leucine, as described in Materials and Methods, were analyzed on a $10 \%$ polyacrylamide SDS gel. $A$ and $B$, Neuron-Schwann cell cultures that had been treated with E-15 medium and were heavily myelinated. $C$ and $D$, Neuron-Schwann cell cultures that had been maintained in N2defined medium and thus contained no myelin. $E$ and $F$, Schwann cells only. $A, C, E$, Sciatic nerve Schwann cells. $B, D, F$, DRG-derived Schwann cells. On the right are indicated the positions of molecular weight standards in kilodaltons.

directly compared to cells derived from embryonic DRG preparations. The two cell populations were seeded at comparable densities $(25,000-50,000)$ onto bare neurite DRG cultures. The Schwann cell-neuron cultures were maintained in N2-defined medium until the Schwann cells had proliferated sufficiently to completely repopulate the surface of the neurites-approximately 2 weeks. The medium was then changed to one (with serum and ascorbate) that promotes myelination. Initially, the sciatic nerve-derived cells appeared larger, although they exhibited the same bipolar spindle shape as did the DRG Schwann cells. Within $1 \mathrm{~d}$ in contact with neurons, both cell groups had aligned themselves on neuronal processes. Few cells could be seen in extraneural regions. Thus, within $24 \mathrm{hr}$, it was clear that the passaged cells had retained their ability both to recognize and associate with axons. Within $2 \mathrm{~d}$ of exposure to neurons, the sciatic nerve cells looked, in size and shape, indistinguishable from the DRG Schwann cells. Furthermore, it appeared that both populations of Schwann cells were expanding in response to the neuronal mitogen. After switching to the myelination medium, signs of myelin segments appeared in both cultures within 1 week. By 2 weeks, both cultures displayed extensive arrays of myelinated axon segments (Fig. 5). The myelination experiment was performed twice, using a sciatic nerve Schwann
Table 1. Quantitation of myelination with Schwann cells from sciatic nerve or DRG

\begin{tabular}{|c|c|c|c|c|}
\hline \multirow{3}{*}{$\begin{array}{l}\text { Segments/ } \\
\text { field }\end{array}$} & \multicolumn{4}{|c|}{ Number of fields } \\
\hline & \multicolumn{2}{|c|}{ Expt. 1 (2 weeks) } & \multicolumn{2}{|c|}{ Expt. 2 (3 weeks) } \\
\hline & DRG & Sciatic & DRG & Sciatic \\
\hline 0 & 0 & 3 & 0 & 0 \\
\hline $1-20$ & 20 & 15 & 0 & 0 \\
\hline $21-40$ & 0 & 3 & 0 & 1 \\
\hline $41-60$ & 0 & 3 & 0 & 0 \\
\hline$>60$ & 0 & 0 & 30 & 29 \\
\hline
\end{tabular}

Neuron-only cultures were seeded with Schwann cells from sciatic nerve or DRG and maintained in conditions that promote myelination. Sudan black-stained preparations, as in Figure 6, were visualized in the light microscope with a $16 \times$ phase objective. The number of complete myelin segments per field was counted. The sciatic nerve Schwann cells used in both experiments were from the same preparation. The experiments were performed 2 and 8 months after dissection of the sciatic nerve cells. The length of time during which myelination was allowed to proceed prior to fixation is indicated in parentheses.

cell population that had been expanded continuously for 2 or 8 months. In both cases, the degree of myelination attained was comparable to that seen with DRG Schwann cells (Table 1). Another culture of sciatic nerve Schwann cells, expanded for 1 month, gave comparable results.

\section{Discussion}

Our aim in initiating these studies was to derive a method of attaining a maximal rate of Schwann cell proliferation in culture while retaining the cells' ability to effectively participate in all types of neuron-Schwann cell interactions. We report here that those goals have been met. Populations of primary Schwann cells can be maintained, expanded, and passaged for several months in culture using a combination of crude glial growth factor and a submitogenic concentration of forskolin. Removal of the mitogenic mixture yields quiescent cells that are capable of responding appropriately to a reexposure to mitogen. The secondary cells that arise retain the ability to (1) express characteristic Schwann cell antigens, (2) secrete the same complement of proteins as Schwann cells maintain in contact with neurons, and (3) bind to and myelinate DRG neurons in culture.

With crude GGF and forskolin, we can attain very high labeling indices of Schwann cells. These data corroborate those of Raff et al. (1978a), which indicate that GGF plus cholera toxin act synergistically in stimulating Schwann cell proliferation, and thus probably function through separate mechanistic pathways. The advantage of forskolin is its reversibility, compared to cholera toxin. As shown in Figure 1, stimulated Schwann cells become quiescent within $4 \mathrm{~d}$ of forskolin removal and are capable of proliferating in response to a reapplication of mitogen. In contrast, Raff et al. (1978b) reported that a single exposure of Schwann cells to cholera toxin would continue to elicit mitogenic effects for more than 2 weeks after removal of the toxin. The role of cyclic AMP in the mitogenic response of Schwann cells remains ill-defined. Although addition of cAMP or agents that increase intracellular levels of cAMP induce a growth response in Schwann cells (Raff et al., 1978b), GGF (Raff et al., 1978a), brain axolemma and myelin membrane fragments (Meador-Woodruff et al., 1984) have been reported to have no effect on detectable cAMP levels. However, Ratner et al. (1984) have shown that mitogenic membranes can induce a detectable increase of intracellular cAMP. Membranes from PC12 cells were shown to be mitogenic for Schwann cells and capable of causing a rise in cAMP, but not until $16 \mathrm{hr}$ after addition to Schwann cells. The extended time necessary to see an effect on cAMP levels closely corresponds with the $22-24 \mathrm{hr}$ necessary 

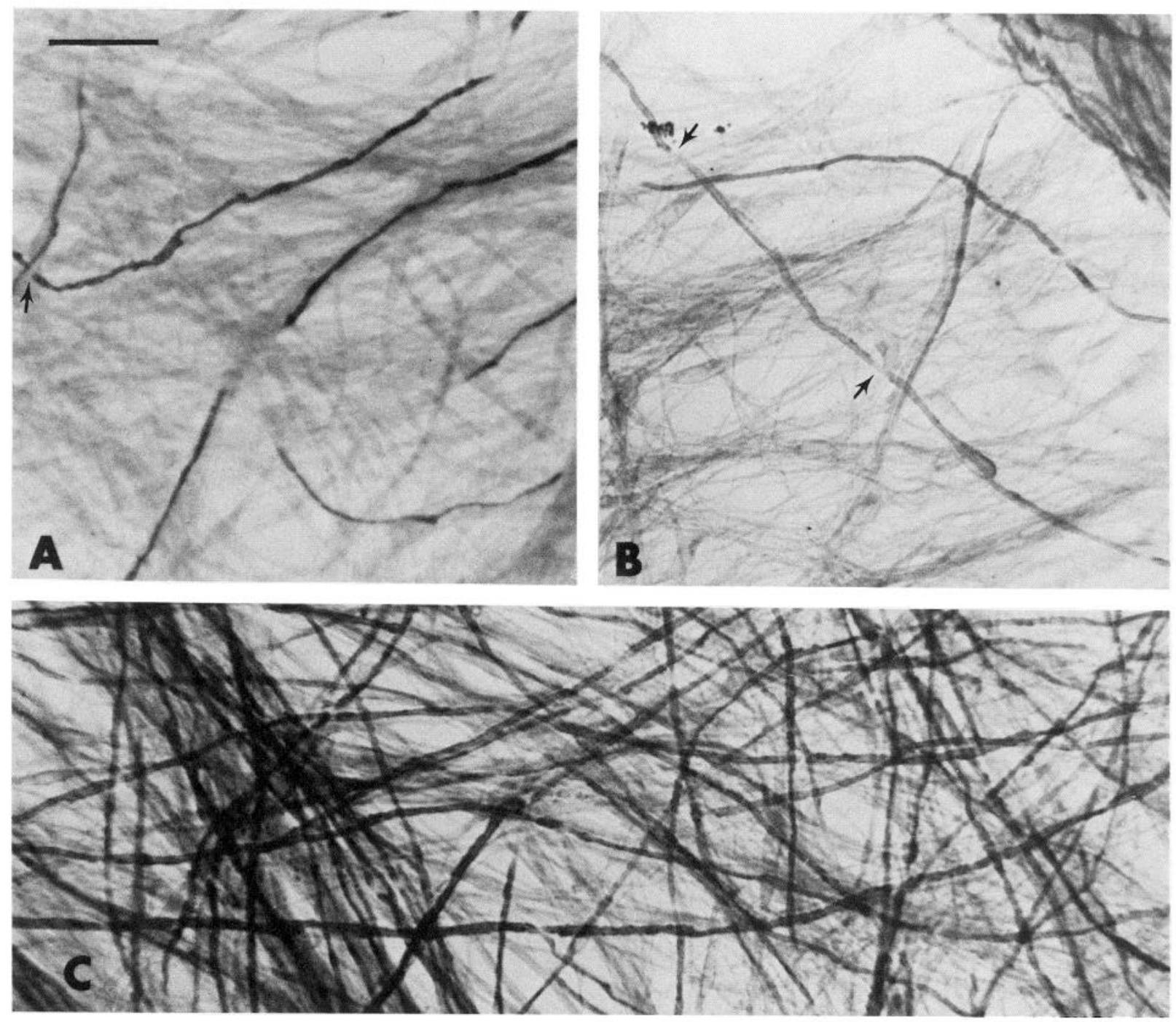

Figure 5. Myelination of DRG neurons with Schwann cells from sciatic nerve or DRG. Sudan black-stained preparations of parallel DRG neurononly cultures that had been seeded with DRG $(A)$ or sciatic nerve $(B, C)$ Schwann cells. $A$ and $B$, Individual myelin segments in which nodes of Ranvier (arrows) are easily seen between adjacent segments. $C$, Another field from the culture shown in $B$, illustrating the degree of myelination attained. Bar in $A, 20 \mu \mathrm{m}$.

to detect maximal uptake of ${ }^{3} \mathrm{H}$-thymidine in response to brain axolemma (Sobue and Pleasure, 1985). Perhaps further study and attention to time periods $12-24 \mathrm{hr}$ after the addition of mitogen would yield comparable effects of GGF and neuronal membrane fragments on cAMP levels.

One of the crucial components for the expansion of Schwann cells in culture is a suitably adhesive surface. Schwann cells are stable in culture on a substratum of tissue-culture plastic or glass, and will respond to mitogens on these surfaces, as detected by autoradiographic visualization of ${ }^{3} \mathrm{H}$-thymidine-labeled nuclei. However, an increase in actual cell number is not observed unless a more adhesive substratum, such as poly-L-lysine, is provided. We conclude that during mitosis, the cells lose their ability to bind tightly to the plastic and therefore detach from it. Why the cells do not reattach, as after trypsinization, is not clear. Nonetheless, culturing the cells on the highly positively charged surface allows us to expand the Schwann cell populations. Previous studies have shown that ammoniated collagen is an effective substratum for the growth of DRG neuronSchwann cell cocultures (Wood, 1976). However, for Schwann cell-only cultures, under the conditions described here, PLL provides a better surface.
In establishing the primary Schwann cell cultures, contaminating fibroblasts are initially reduced by a $3 \mathrm{~d}$ pulse of cytosine arabinoside followed by periodic treatments with anti-Thy 1.1 and complement. The combination of these treatments appears to be the most effective means for eliminating fibroblasts so that they comprise less than $1 \%$ of the cell population. Others have used simple cell-separation techniques to avoid potentially deleterious effects of antimitotic treatment (Kalderon, 1984; Kreider et al., 1982). Yet we have found that, even after extended time in culture, Schwann cells that had been treated with cytosine arabinoside retained full function.

While rat sciatic nerves provide greater numbers of Schwann cells in a much shorter time than do embryonic DRG from a comparable number of animals, it has been reported that the sciatic nerve cells generally have a higher background incorporation of ${ }^{3} \mathrm{H}$-thymidine than do the DRG-derived cells (Brockes et al., 1979; Raff et al., 1978a). We have found this to be true in naive, recently dissected cells (average background labeling index $=4.8, N=33$ ). However, those cells that have been extensively cultured exhibit lower background incorporations (average background labeling index $=1.0, N=14$ ). Thus, extended culture of sciatic nerve Schwann cells, even ones that 
have been previously stimulated with mitogens, yields cells that are quiescent unless properly stimulated with mitogens. The question of how long Schwann cell populations can be expanded and still retain properties of naive Schwann cells must be raised. We now have evidence to indicate that Schwann cells repeatedly stimulated and passaged for a period greater than 3 to 4 months can lose their normal growth properties. Interestingly, changes in growth characteristics (failure to attain quiescence after mitogen withdrawal) were not directly followed by failure of the ability to express functional properties. These observations will be the subject of a future communication.

Schwann cells not contacted by neurons cease to express galactocerebroside (Mirsky et al., 1980) and do not form a basal lamina (M. B. Bunge et al., 1982), although some basal lamina components continue to be synthesized (R. P. Bunge et al., 1986). After recombining with neurons under the proper conditions, the Schwann cells again express galactocerebroside (C. F. Eldridge, personal communication), form a basal lamina, and differentiate into an ensheathing and myelin-forming phenotype (R. P. Bunge et al., 1986). Therefore, Schwann cells propagated and passaged with the methods described here can be used not only for studies of the growth response of a normal, nontransformed cell, but also for investigations into the control of expression of myelin-specific gene products.

\section{References}

Aguayo, A. J., J. M. Peyronnard, L. C. Terry, J. S. Romine, and G. M. Bray (1976) Neonatal neuronal loss in rat superior cervical ganglia: Retrograde effects on developing preganglionic axons and Schwann cells. J. Neurocytol. 5: 137-155.

Asbury, A. K. (1967) Schwann cell proliferation in developing mouse sciatic nerve. J. Cell Biol. 34: 735-743.

Bottenstein, J. E., and G. H. Sato (1979) Growth of a rat neuroblastoma cell line in serum-free supplemented medium. Proc. Natl. Acad. Sci. USA 76: 514-517.

Brockes, J. P., and M. C. Raff (1979) Studies on cultured rat Schwann cells. II. Comparison with a rat Schwannoma cell line. In Vitro 15: 772-778.

Brockes, J. P., K. P. Fields, and M. C. Raff (1979) Studies on cultured rat Schwann cells. I. Establishment of purified populations from cultures of peripheral ncrve. Brain Res. 165: 105-108.

Brockes, J. P., G. E. Lemke, and D. R. Balzer (1980) Purification and preliminary characterization of glial growth factor from the bovine pituitary. J. Biol. Chem. 255: 8374-8377.

Bunge, M. B., A. K. Williams, P. M. Wood, J. Uitto, and J. Jeffrey (1980) Comparison of nerve cell and nerve cell plus Schwann cell cultures, with particular emphasis on basal lamina and collagen formation. J. Cell Biol. 84: 184-202.

Bunge, M. B., A. K. Williams, and P. M. Wood (1982) Neuron-Schwann cell interaction in basal lamina formation. Dev. Biol. 92: 449-460.

Bunge, R. P., M. B. Bunge, and C. F. Eldridge (1986) Linkage between axonal ensheathment and basal lamina production by Schwann cells. Annu. Rev. Neurosci. 9: 305-328.

Carey, D. J., and R. P. Bunge (1981) Factors influencing the release of protcins by cultured Schwann cells. J. Cell Biol. 91: 666-672.

Cassel, D., and T. Pfeuffer (1978) Mechanism of cholera toxin action: Covalent modification of the guanyl nucleotide-binding protein of the adenylate cyclase system. Proc. Natl. Acad. Sci. USA 75:2669-2673.

Cornbrooks, C. J., D. J. Carey, J. A. McDonald, R. Timpl, and R. P. Bunge (1983) In vivo and in vitro observations on laminin production by Schwann cells. Proc. Natl. Acad. Sci. USA 80: 3850-3854.

Darfler, F. J., L: C. Mahan, A. M. Koachman, and P. A. Insel (1982) Stimulation by forskolin of intact $\$ 49$ lymphoma cells involves the nucleotide regulatory protein of adenylate cyclase. J. Biol. Chem. 257 : 11901-11907.

Eldridge, C. F., M. B. Bunge, and R. P. Bunge (1985) Serum ascorbic acid regulates myelin formation and basal lamina assembly by Schwann cells in vitro. Soc. Neurosci. Abstr. 11: 986.

Fields, K. L., and M. Dammerman (1985) A monoclonal-antibody equivalent to anti-rat neural antigen-1 as a marker for Schwann cells. Neuroscience 15: 877-885.
Fields, K. L., C. Gosling, M. Megson, and P. L. Stern (1975) New cell surface antigens in rat defined by tumours of the nervous system. Proc. Natl. Acad. Sci. USA 72: 1296-1300.

Gill, D. M., and R. Meren (1978) ADP-ribosylation of membrane proteins catalyzed by cholera toxin: Basis of the activation of adenylate cyclase. Proc. Natl. Acad. Sci. USA 75: 3050-3054.

Kalderon, N. (1984) Schwann cell proliferation and localized proteolysis: Expression of plasminogen-activator activity predominates in the proliferating cell populations. Proc. Natl. Acad. Sci. USA 81 . $7216-7220$.

Kreider, B. Q., A. Messing, H. Doan, S. O. Kim, R. P. Lisak, and D. E. Pleasure (1981) Enrichment of Schwann cell cultures from neonatal rat sciatic nerve by differential adhesion. Brain Res. 207: 433444.

Kreider, B. Q., J. Corey-Bloom, R. P. Lisak, H. Doan, and D. E. Pleasure (1982) Stimulation of mitosis of cultured rat Schwann cells isolated by differential adhesion. Brain Res. 237: 238-243.

Kruse, J., R. Mailhammer, H. Wernecke, A. Faissner, I. Sommer, C. Gorides, and M. Schachner (1984) Neural cell adhesion molecules and myclin-associated glycoprotein share a common carbohydrate moiety recognized by monoclonal antibodies L2 and HNK 1 . Nature 311: 153-155.

Kruse, J., G. Keilhauer, A. Faissner, R. Timpl, and M. Schachner (1985) The J1 glycoprotein - a novel nervous system cell adhesion molecule of the L2/HNK-1 family. Nature 316 : 146-148.

Laemmli, U. K. (1970) Cleavage of structural proteins during the assembly of the head of the bacteriophage T4. Nature 227:680-682.

Lemke, G. E., and J. P. Brockes (1984) Identification and purification of glial growth factor. J. Neurosci. 4: 75-83.

Meador-Woodruff, J. H., B. L. Lewis, and G. H. Devries (1984) Cyclic AMP and calcium as potential mediators of stimulation of cultured Schwann cell proliferation by axolemma-enriched and myelin-enriched membrane fractions. Biochem. Biophys. Res. Commun. 122 : 373-380.

Mirsky, R. J., J. Winter, E. R. Abney, R. M. Pruss, J. Gavrilovic, and M. C. Raff (1980) Myelin-specific proteins and glycolipids in rat Schwann cells and oligodendrocytes in culture. J. Cell Biol. 84: 483494.

Moya, F. R., R. P. Bunge, and M. B. Bunge (1980) Schwann cells proliferate but fail to differentiate in defined medium. Proc. Natl. Acad. Sci. USA 77: 6902-6906.

Peng, W. W., J. P. Bressler, E. Tiffany-Castiglioni, and J. de Vellis (1982) Development of a monoclonal antibody against a tumorassociated antigen. Science 215: 1102-1104.

Raff, M. C., E. Abney, J. P. Brockes, and A. Hornby-Smith (1978a) Schwann cell growth factors. Cell 15: 813-822.

Raff, M. C., A. Hornby-Smith, and J. P. Brockes (1978b) Cyclic AMP as a mitogenic signal for cultured rat Schwann cells. Nature 273:672673.

Rathjen, F. G., and M. Schachner (1984) Immunocytological and biochemical characterization of a new neuronal cell surface component ( $\mathrm{L} 1$ antigen) which is involved in cell adhesion. EMBO J. 3: 110.

Ratner, N., L. Glaser, and R. P. Bunge (1984) PCl2 cells as a source of neurite-derived cell surface mitogen, which stimulates Schwann cell division. J. Cell Biol. 98: 1150-1155.

Ratner, N., R. P. Bunge, and L. Glaser (1985) A neuronal cell surface heparan sulfate proteoglycan is required for dorsal root ganglion neuron stimulation of Schwann cell proliferation. J. Cell Biol. 101: 744754.

Salzer, J. L., and R. P. Bunge (1980) Studies of Schwann cell proliferation. I. $\Lambda \mathrm{n}$ analysis in tissue culture of proliferation during development, Wallerian degeneration, and direct injury. J. Cell Biol. 84: 739-752.

Salzer, J. L., R. P. Bunge, and L. Glaser (1980a) Studies of Schwann cell proliferation. III. Evidence for the surface localization of the neurite mitogen. J. Cell Biol. 84: 767-778.

Salzer, J. L., A. K. Williams, L. Glaser, and R. P. Bunge (1980b) Studies of Schwann cell proliferation. II. Characterization of the stimulus and specificity of the response to a neurite membrane fraction. J. Cell Biol. 84: 753-766.

Seamon, K., and J. W. Daly (1981a) Activation of adenylate cyclase by the diterpene forskolin does not require the guanine nucleotide regulatory protein. J. Biol. Chem. 256: 9799-9801.

Seamon, K. B., and J. W. Daly (1981b) Forskolin: A unique diterpene 
activator of cyclic AMP-generating systems. J. Cyclic Nucleotide Res. 7: 201-224.

Sobue, G., and D. Pleasure (1985) Adhesion of axolemmal fragments to Schwann cells: A signal- and target-specific process closely linked to axolemmal induction of Schwann cell mitosis. J. Neurosci. 5: 379387

Stengel, D., L. Guenet, M. Desmier, P. Insel, and J. Hanoune (1982) Forskolin requires more than the catalytic unit to activate adenylate cyclase. Mol. Cell. Endocrinol. 28: 681-690.
Webster, H. deF., and J. T. Favilla (1984) Development of peripheral nerve fibers. In Peripheral Neuropathy, Vol. 1, P. J. Dyck, P. K. Thomas, E. H. Lambert, and R. Bunge, eds., pp. 329-359, W. B. Saunders, Philadelphia, PA.

Wood, P. M. (1976) Separation of functional Schwann cells and neurons from normal peripheral nerve tissue. Brain Res. 115: 361-375. 